\title{
Reconstructed index of summer monsoon dry-wet modes in East Asia for the last millennium
}

\author{
QIAN WeiHong", ZHU YaFen \& TANG ShuaiQi \\ Monsoon and Environment Research Group, School of Physics, Peking University, Beijing 100871, China
}

Received March 2, 2011; accepted July 14, 2011

\begin{abstract}
Monthly precipitation datasets collected at 160 stations in China as well as the monthly winds and humidity data derived from the US National Centers for Environmental Prediction (NCEP) were used to construct the relationship between six summer dry-wet modes in eastern China and the summer monsoon airflow northward advance in East Asia. A millennial series of the monsoon dry-wet index (MDWI) was reconstructed based on Wang's six summer dry-wet modes in eastern China since 950 AD. A high (low) index indicates that the strong (weak) East Asian summer monsoon airflow can reach northern (southern) China and cause above (below) normal precipitation. Interdecadal periodic variations, such as the approximate 70-year oscillation, can be found in the MDWI series. In the last millennium, northern China has experienced persistent decadal wet periods and persistent decadal dry periods. At present, the MDWI is a low period on the interdecadal time scale so above-normal precipitation is observed in southern China and below-normal precipitation in northern China.
\end{abstract}

reconstructed monsoon index, millennial series, dry-wet mode, interdecadal variability, East Asia

Citation: Qian W H, Zhu Y F, Tang S Q. Reconstructed index of summer monsoon dry-wet modes in East Asia for the last millennium. Chinese Sci Bull, 2011, 56: 3019-3027, doi: 10.1007/s11434-011-4714-6

China is located in the eastern monsoon area, which has frequent regional or valley droughts or flood events each year. Using in situ precipitation data collected over 54 years (1951-2004), Ding et al. [1] suggested that there was a dipole pattern and a tripole (positive-negative-positive) pattern of summer precipitation in eastern China based on the interdecadal variability, with two abrupt climate turning points in 1978 and 1992. Meanwhile, precipitation records from 25 sites [2] in eastern China for 123 years (1880-2002) were used to identify near-80-year, 30-40-year and 12-year oscillations, which play important roles in the regional dry-wet interdecadal variability. Yang et al. [3] proposed that there was an increase of boreal-summer precipitation over the Yangtze River and a decrease over North and South China, with an abrupt climate turning point occurring in 1974-1975, using summer precipitation data from 1951 to 1998 . Chang et al. [4] noted that an abrupt climate turn-

*Corresponding author (email: qianwh@pku.edu.cn) ing point of summer precipitation over the Yangtze River occurred in 1977-1978 using a precipitation dataset from 1951 to 1996. Most studies used precipitation data since 1951 and found that an abrupt climate turning point of the summer precipitation over the Yangtze River occurred in the late 1970s [5].

In eastern China, summer droughts or floods in North China and South China, particularly along the Yangtze River basin, have been widely studied by researchers. Furthermore, additional two summer precipitation modes have appeared since 1951. One mode is dry and experienced in eastern China. For example, summer precipitation was much lower than the normal level in 1960 and 1972. Another mode is wet and was experienced in 1954 and 1998, with above normal levels of precipitation in eastern China. There were six modes of summer precipitation in eastern China, these two additional modes and the four modes from the dipole pattern and the positive-negative-positive pattern [1]. 
The Yangtze River basin is a famous summer monsoon (Meiyu) region and whether the summer monsoon is strong or weak determines the probability of regional drought or flood in a year. Many indices of the East Asian summer monsoon have been constructed and indicate the dry-wet variations along the Yangtze River basin [6-11]. Recently, two studies tried to construct regional monsoon indices and indicate the dry-wet variations in North China and South China $[12,13]$. For each year, the advance of the summer southerly monsoon airflow determines the dry-wet distribution mode. Based on this, we aimed to construct an index that can indicate the advance of the summer southerly airflow in East Asia and the dry-wet distribution mode in eastern China. A millennial series of the East Asian summer monsoon index is also necessary to investigate the interdecadal variability.

The aim of this study was to extend research on the East Asian summer monsoon in three aspects. The first was to extend the study from four modes of dipole and tripole patterns to six modes, including the whole dry mode and the whole wet mode in eastern China. The second was to identify the relationship between the six precipitation modes in eastern China and moisture transport by the summer monsoon airflow in East Asia. The third was to reconstruct the monsoon dry-wet index (MDWI) of the East Asian summer monsoon based on the six precipitation modes from the last half century to the last millennium and to study its interdecadal variability.

\section{Summer precipitation modes}

The unique topography in China, particularly the Tibetan Plateau in the southwest, has a strong influence on the intensity and location of the subtropical monsoon. It is well known that the westerly dry-cool flow to the north of the Tibetan Plateau and the southerly warm-humid monsoon flow over eastern China converge in the leeward side of the Tibetan Plateau and form a subtropical frontal zone and rainy belt extending from eastern China to Japan. Climatologically, this frontal zone gradually moves from South China to the Yangtze River, even to North China during May and late July. However, the advance of the rainy belt and regional precipitation intensity differ from year to year.
Thus, we chose the precipitation departure (or dry-wet grades) to compare the differences of inter-regional rainfall. Five dry-wet grades (Table 1) based on each station's climatic mean precipitation and its standard deviation from May to September for the period 1951-2008 were calculated using the monthly 160 -station precipitation dataset in China. Details of the calculation have been described previously [14]. Lower values of the grade indicate greater amounts of precipitation while higher values indicate less precipitation.

Climatic departures of each summer (May-September) precipitation percentage for 1951-2008 were first calculated and 25 typical summers of the dry-wet distribution were grouped into the six dry-wet modes (Table 2). The spatial distributions of the six dry-wet modes are shown in Figure 1. During the last 58 years, one kind of typical summers was 5 years, with below normal precipitation in eastern China, above normal precipitation over the Yangtze River basin, and above and below normal precipitation over the south of Yangtze River, respectively. By contrast, typical summers were 3 years, with below normal precipitation over the Yangtze River basin, and above normal precipitation in North China and South China. In the last 58 years, typical summers with above normal precipitation were more frequent than those with below normal precipitation over the Yangtze River basin. Typical summers with above normal precipitation in eastern China occurred only in 1954 and 1998. Dry-wet distributions for all typical summers illustrated that the dry mode had a high frequency in eastern China, while for the wet mode, it was in the south of the Yangtze River. The six dry-wet modes include the four modes based on the dipole pattern and tripole pattern [1]. In Figure 1, modes 2

Table 1 Five dry-wet grades and precipitation departures

\begin{tabular}{ll}
\hline Dry-wet grades & \multicolumn{1}{c}{ Formula } \\
\hline 1 (flood) & $R_{i}>(R+1.17 \sigma)$ \\
2 (wet) & $(R+0.33 \sigma)<R_{i} \leqslant(R+1.17 \sigma)$ \\
3 (normal) & $(R-0.33 \sigma)<R_{i} \leqslant(R+0.33 \sigma)$ \\
4 (dry) & $(R-0.33 \sigma)<R_{i} \leqslant(R-1.17 \sigma)$ \\
5 (drought) & $R_{i} \leqslant(R-1.17 \sigma)$ \\
\hline
\end{tabular}

$R_{i}$ is the observed station summer (May-September) total rainfall in the $i$ th year, $R$ and $\sigma$ are the climatic average of the total summer rainfall and its standard deviation during 1951-1990.

Table 2 Dry-wet index and six sets of typical dry-wet years

\begin{tabular}{|c|c|c|}
\hline Index & Precipitation mode & Year \\
\hline 1 & below-normal rainfall in eastern China & $1960,1965,1972,1986,2001$ \\
\hline 2 & above-normal and below-normal rainfall in the south and north of the Yangtze River, respectively & $1952,1970,1993,1999,2002$ \\
\hline 4 & above-normal rainfall in eastern China & 1954,1998 \\
\hline 5 & below-normal and above-normal rainfall in the south and north of the Yangtze River, respectively & $1956,1958,1964,1985,2003$ \\
\hline 6 & below-normal rainfall along the Yangtze River but above-normal rainfall in North and South China & $1959,1961,1973$ \\
\hline
\end{tabular}



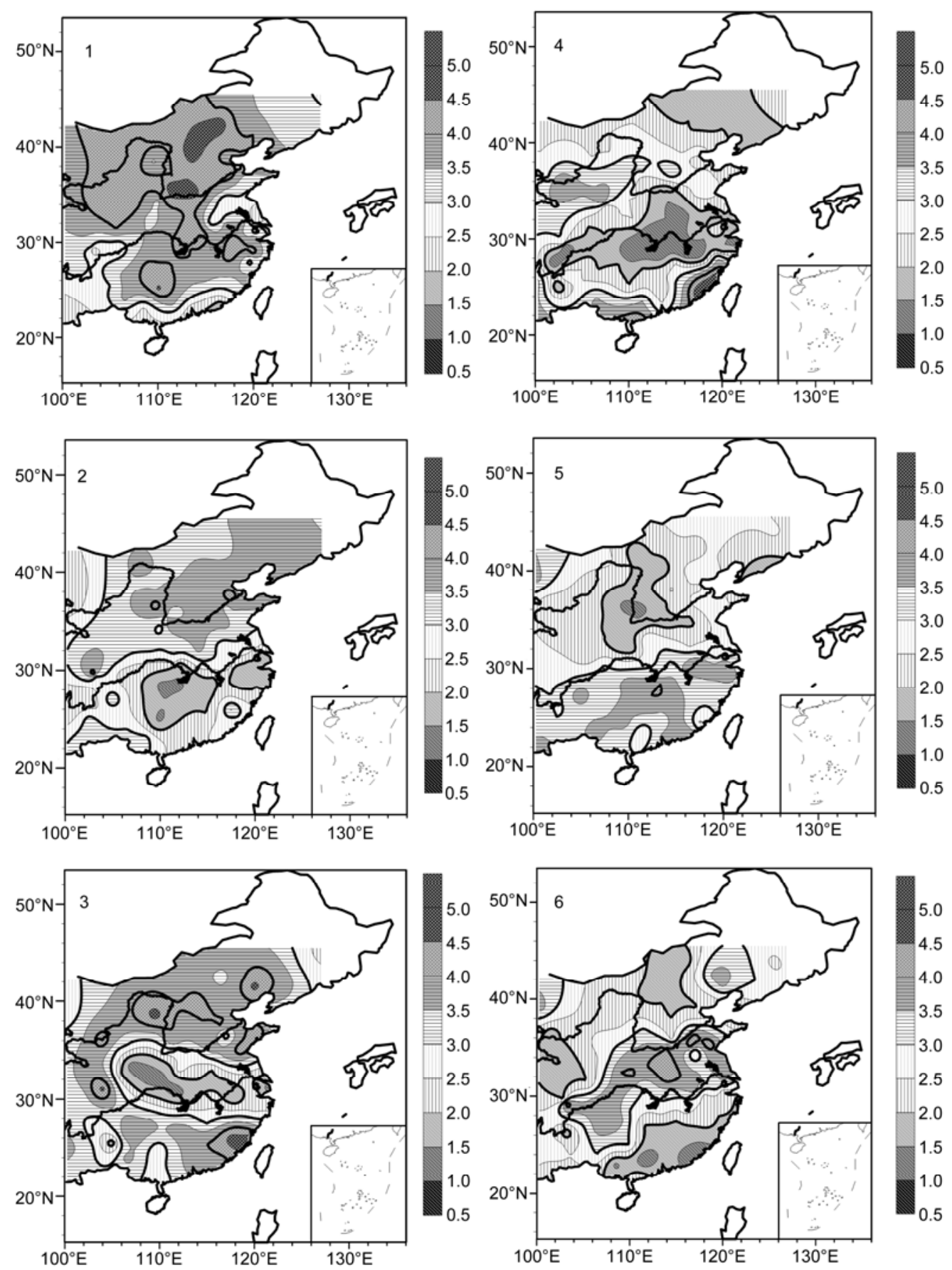

Figure 1 Six dry-wet modes based on the composite of total summer (May-September) rainfall from six sets of typical dry-wet years in Table 2 (five dry-wet grades are from Table 1).

and 5 correspond to the dipole pattern and modes 3 and 6 correspond to the tripole pattern. Modes 1 and 4 are for the dry and the wet distributions in the whole eastern part of the country.

\section{Monsoon dry-wet index}

Each year, the dry or wet mode is determined by the strength of the southerly monsoon airflow or moisture transport. Because of this association, the large-scale circulation effects can be identified by the dry-wet mode. Moisture transport from the lower troposphere based on the monthly winds and specific humidity derived from the US National Centers for Environmental Prediction (NCEP) at the levels of 1000, 925, $850,700,600$ and $500 \mathrm{hPa}$ and at 2.5 by 2.5 latitude-longitude grids were calculated [15].

Figure 2 shows the lower troposphere moisture transport 

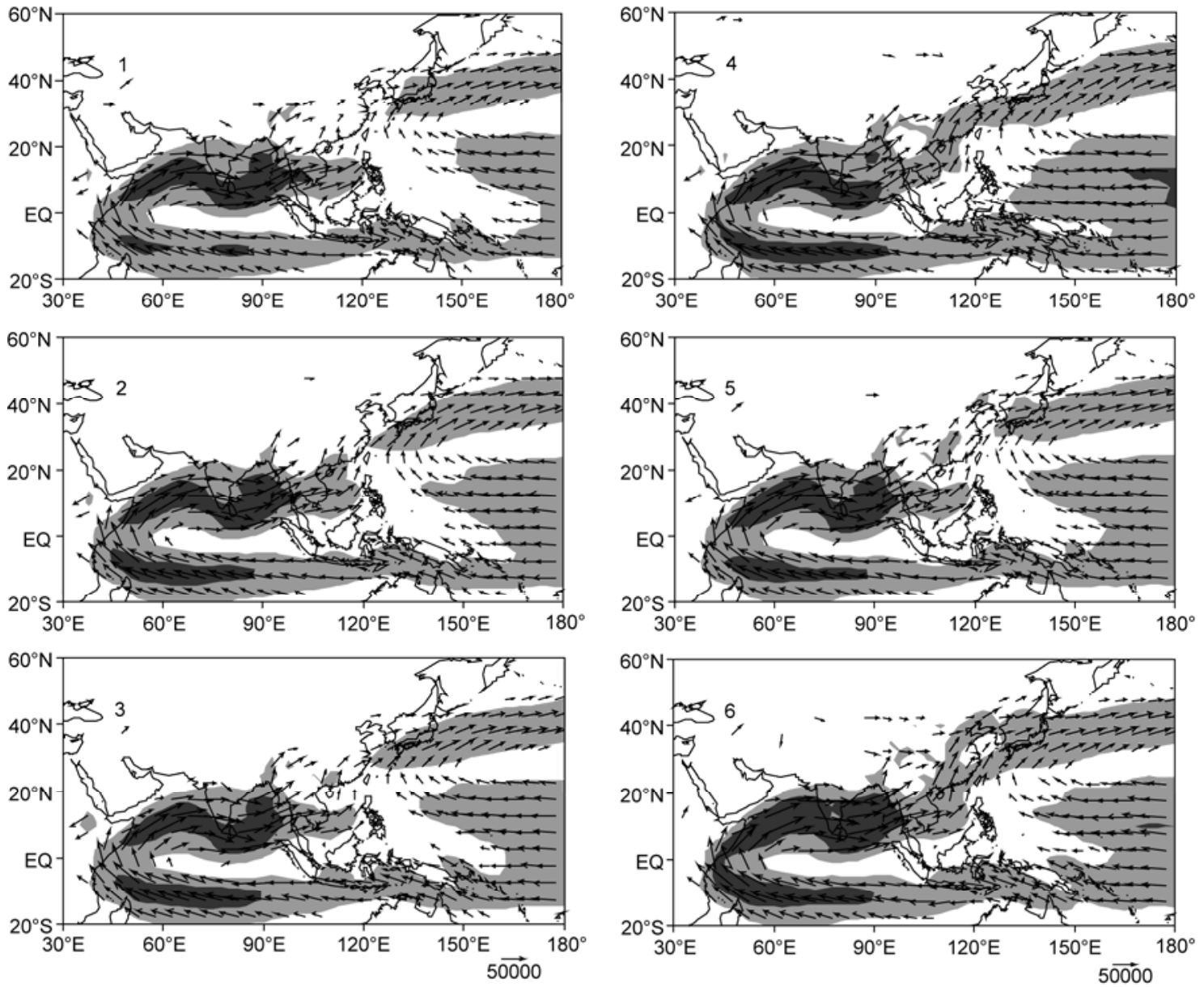

Figure 2 Composites of low-troposphere moisture transports from the surface to $500 \mathrm{hPa}$ based on six sets of typical dry-wet years in Table 2. Vectors

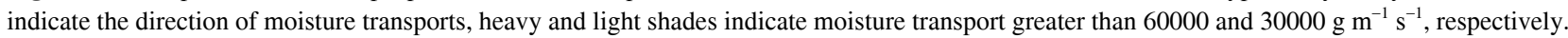

that was based on each dry-wet mode of typical summers presented in Table 2. These illustrated that (1) the dry mode in eastern China corresponded to lower than average moisture transport over the land; (2) greater precipitation in the south of Yangtze River corresponded to greater moisture transport reaching the south coast; (3) greater precipitation over the Yangtze River corresponded to greater moisture transport reaching the river; (4) the wet mode in eastern China corresponded to greater moisture transport than the average over the land; (5) greater precipitation over North China corresponded to greater moisture transport reaching North China; and (6) below normal precipitation over the Yangtze River and above normal precipitation in North China and South China corresponded to greater moisture transport reaching North China and South China than that over the Yangtze River. The relationships between the data presented in Figures 1 and 2 become clear by analyzing these dry-wet modes and the lower troposphere moisture transport in eastern China. The moisture transport in eastern China mainly comes from the Bay of Bengal and the South China Sea. The monsoon is formed by the thermal contrast between the nearby sea and land. Moisture transports shown in Figure 2 indicated that the thermal contrast is not only from the Pacific and Asian land [4,8], but also from the peninsula sea-land thermal contrasts, such as those in the Indian Peninsula and the Bay of Bengal as well as in the Indo-China Peninsula and the South China Sea [16].

The six modes can be determined and compared from each summer precipitation departure in eastern China. The summer monsoon dry-wet mode index (MDWI) series from 1951 to 2008 in East Asia and its standardized departure series with 7-point running averages are shown in Figure 3. During 1951-2008, modes 1-6 were in 10, 12, 17, 2, 12 and 5 years, respectively. Modes with a greater numbers of years indicate that above normal levels of precipitations occurred more easily over the Yangtze River basin, South China and North China. The series of standardized departures with 7-point running averages indicate that there is an association between the dry-wet mode and the East Asian monsoon intensity variations in the interdecadal time scale.

Two periods, each of 11 years, from 1956-1966 and 1992-2002 are shown in Figure 3(b). As presented in Figure 4 , above normal precipitation occurred in northern China during the former period, with a high index series, and 

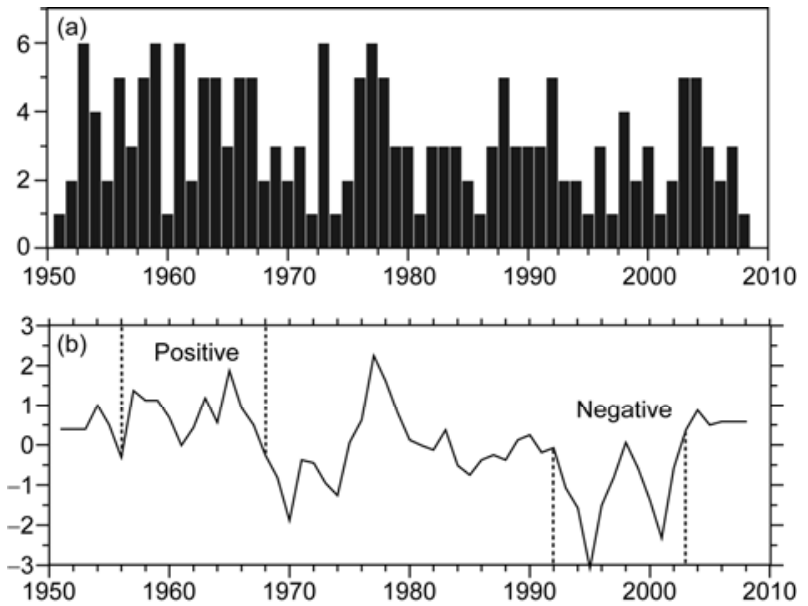

Figure 3 East Asian summer MDWI. (a) Constructed MDWI series for 1951-2008; (b) 7-point running mean MDWI series after standardized departure, "positive" and "negative" indicate two different periods.

above normal precipitation occurred in southern China during the latter period, with a low index. During 1956-1966, above normal precipitation occurred from Southwest China to North China and Northeast China as well as along the south coast of South China; below normal precipitation occurred over the south of mid-low Yangtze River and Northwest China. During 1992-2002, there was above normal precipitation in the south of Yangtze River, while there was normal or below normal precipitation in other regions. Figure 4 indicates that there was interdecadal variability of precipitation distribution mode in the East Asian monsoon region.

For these two periods, 1956-1966 and 1992-2002, summer mean moisture transport and their departure relative to climatology were calculated (figure omitted). During the first period, moisture could travel from the Indian Ocean and the South China Sea to northern China with the southwesterly anomalous moisture transport over eastern China and East Asia. During the latter period, moisture could only travel from the Indian Ocean to the southern fringe seas of the Asian continent with the northeasterly anomalous flow over eastern China and East Asia. The opposite distributions of circulation anomalies and precipitation departures observed in eastern China show that there is a distinguishable relationship on the interdecadal time scale. On the interdecadal time scale, our results from this analysis were similar with the results of Ding et al. [1] based on vertical mean moisture transport from the surface to $300 \mathrm{hPa}$.

\section{Comparison of various monsoon indices}

The aim of the constructed monsoon index is to quantitatively reflect the climate change or monsoon intensity in the East Asian region. Seven East Asian monsoon indices constructed in previous studies are listed in Table 3. The summer monsoon index (SMI) of Guo [6] was defined by the sum zonal difference of summer sea-level pressure (SLP) between two longitudes $110^{\circ}$ and $160^{\circ} \mathrm{E}$ with the condition $P_{110^{\circ}-160^{\circ} \mathrm{E}} \leqslant 5 \mathrm{hPa}$ and those points at $10^{\circ}$ latitude intervals from $10^{\circ}$ to $50^{\circ} \mathrm{N}$. The monsoon index (MI) of Shi et al. [7] was calculated by the sum of the standardized SLP differences from those points at $5^{\circ}$ latitude intervals from $20^{\circ}$ to $50^{\circ} \mathrm{N}$ and between two longitudes $110^{\circ}$ and $160^{\circ} \mathrm{E}$. The Asian-Pacific oscillation (APO) index with the formula

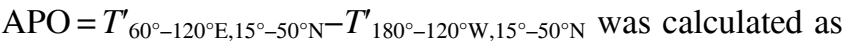
a two regional eddy temperature difference [8]. The East Asian monsoon index (EAMI) was calculated by the sum of the standardized shear $\left(U_{850}-U_{200}\right)$ from 850 and $200 \mathrm{hPa}$

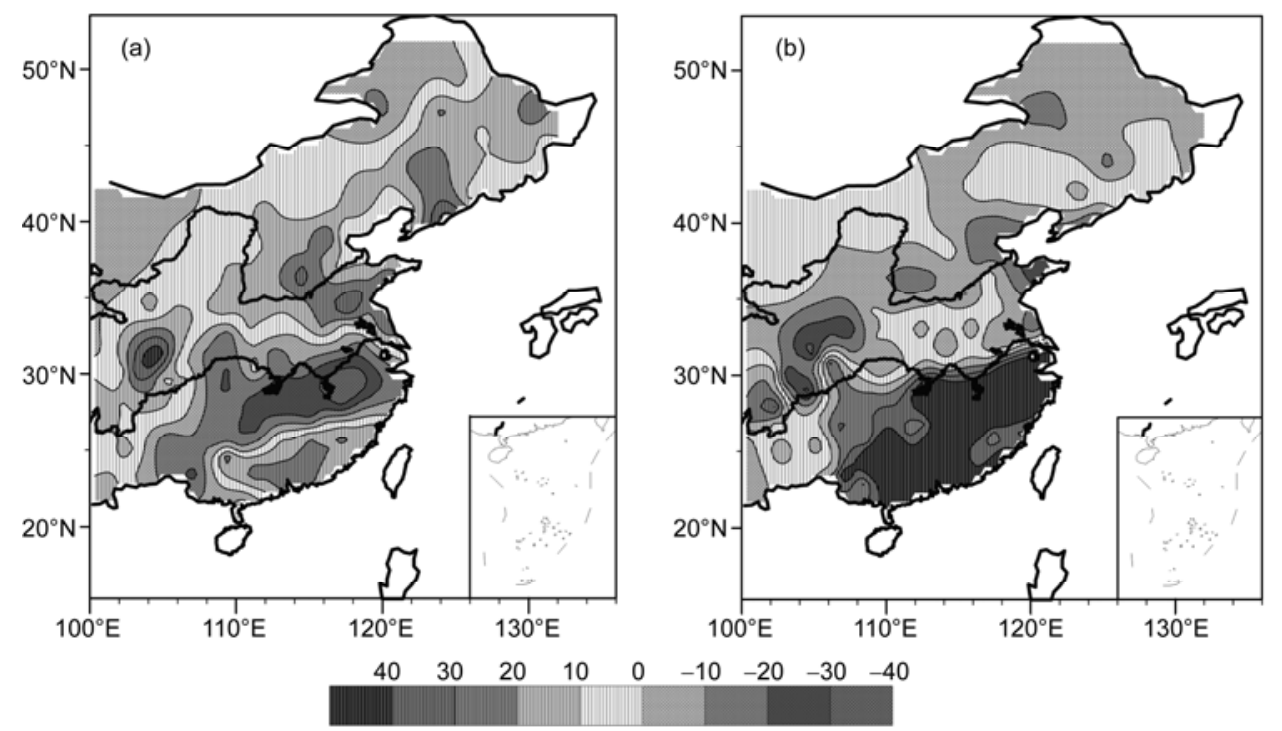

Figure 4 Composites of summer rainfall percentage $(\%)$ in two periods. Dotted line and shading areas indicate the percentages $\leqslant 0$, and the contour interval is $10 \%$. (a) 1956-1966; (b) 1992-2002. 
Table 3 Correlation coefficients between the East Asian summer MDWI and the other seven indexes ${ }^{\text {a) }}$

\begin{tabular}{llcccccc}
\hline Correl & SMI & MI & APO & EAMI & EASMI & TCIX & SAMI \\
\hline MDWI & 0.39 & -0.35 & 0.29 & -0.21 & -0.14 & 0.12 & -0.03 \\
SMI & 1 & -0.8 & 0.75 & -0.63 & -0.24 & 0.23 & 0.23 \\
MI & & 1 & -0.64 & 0.57 & 0.15 & 0.18 & -0.12 \\
APO & & & 1 & -0.37 & 0.001 & 0.34 & 0.34 \\
EAMI & & & & 1 & 0.70 & 0.58 & 0.18 \\
EASMI & & & & & 1 & 0.67 & 0.13 \\
TCIX & & & & & & 1 & 0.50 \\
\hline
\end{tabular}

a) Significance levels reach $0.01,0.05,0.10$ and 0.15 when their correlation coefficient values are $0.335,0.258,0.218$ and 0.194 .

zonal winds over the area $0^{\circ}-10^{\circ} \mathrm{N}, 100^{\circ}-130^{\circ} \mathrm{E}$ and the standardized SLP differences from $10^{\circ}$ to $50^{\circ} \mathrm{N}$ and between two longitudes, $110^{\circ}$ and $160^{\circ} \mathrm{E}$ [9]. The East Asian summer monsoon index (EASMI) was defined by Zhang et al. [10] and calculated based on the difference of the zonal wind anomaly at $850 \mathrm{hPa}$ level from the regions of tropical monsoon trough $\left(10^{\circ}-20^{\circ} \mathrm{N}, 100^{\circ}-150^{\circ} \mathrm{E}\right)$ and the Meiyu trough $\left(25^{\circ}-35^{\circ} \mathrm{N}, 100^{\circ}-150^{\circ} \mathrm{E}\right)$ from June to August. A tropical circulation index (TCIX) was defined based on the tropical wind vertical shear in the South China Sea region and is associated with the Walker circulation [11]. The South Asian monsoon index (SAMI) was defined by the zonal wind shear from 850 and $200 \mathrm{hPa}$ levels over the South Asian tropical region $\left(5^{\circ}-20^{\circ} \mathrm{N}, 40^{\circ}-110^{\circ} \mathrm{E}\right)$ [17].

In total, there are eight monsoon indices, including the MDWI. Eight maps showing the correlation between the summer (May-September) precipitation and each monsoon index are plot in Figure 5. For our MDWI index, opposite correlations are observed in northern China and southern China, separated by the Yangtze River. There is no regional correlation for the SAMI because it does not include any atmospheric variable information on the Asian continent and Pacific regions. The other six indices can indicate the dry and wet features of the region along the Yangtze River. These six indices contain information on various differences of temperature, pressure, and circulation between the Asian continent and the Pacific regions. Figure 2 shows that MDWI is closely linked to the monsoon flows from the Indian Ocean and Pacific Ocean as well as the thermal contrasts between the two oceans and the Asian continent.

Table 3 lists the correlations between the MDWI and the other seven indices. Higher correlations are those with sea-land thermal contrast and pressure difference; the correlations for SMI, MI and APO reached the 0.01, 0.01 and 0.05 significance levels. Lower correlations were found for EASMI, TCIX and SAMI, which had correlation values of $-0.14,0.12$ and -0.03 , respectively. The correlation coefficient between MDWI and EAMI was -0.21 , reaching the 0.10 significance level. The index of EAMI was constructed
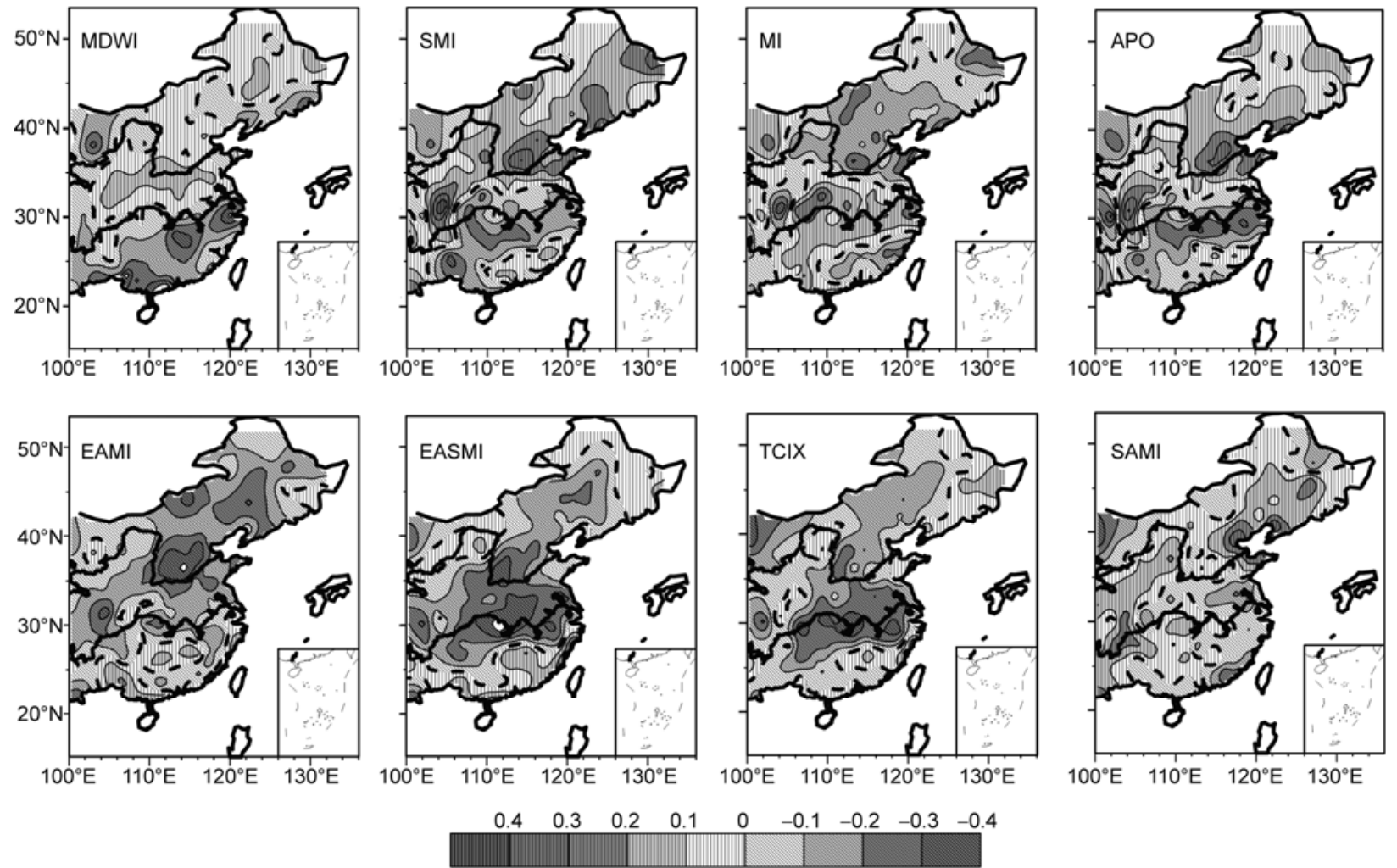

Figure 5 Correlation distributions between the eight summer monsoon indices and summer (May-September) rainfall in eastern China for 1951-2008. Dotted line and shading areas indicate the correlation coefficients $\geqslant 0$, and the coutour interval is 0.1 . 
based on data of the sea-land thermal contrast and circulation.

\section{Millennial monsoon dry-wet index series}

In a comparative analysis, Wang [18] examined the empirical orthogonal function (EOF) derived from data of annual records of dryness/wetness in China for 500 years since 1470 , and from instrumental precipitation collected during recent decades. His EOF results confirmed that the two data sets are nearly identical in spatial variations, which indicates that conversion from the instrumentation data to the wet-dry intensity scale is reliable. While examining the data consistency, Wang et al. [19] explored additional historical sources of dry-wet data and extended the historical rainfall records from 1470 back to $950 \mathrm{AD}$. Wang extended his series to the last 1000 years with six dry-wet anomaly modes that are similar to those shown in Figure 1 in eastern China. By using Wang's annual dry-wet anomaly modes and the instrumental precipitation data, Qian et al. [20] updated these modes to 1999 and extracted five dry-wet grades in the three regions over North China, the Yangtze River and South China. Periodic variations of dry-wet series for each individual region are easy to identify. However, it is difficult to determine the spatial structure of the dry-wet distribution and its evolution over time. In this study, we updated Wang's dry-wet modes from 950 to 2008 and transformed each annual mode into one of six numbers based on Figures 1 and 3(a). Figure 6(a) plots the East Asian summer MDWI series from 950 to 2008. In Figure 6(a), numbers 1 to 6 indicate modes as shown in Figure 3(a). The standardized departure series for the last millennium with 7-point and 21-point running averages are shown in Figure 6(b).

In the last millennium, the weakest summer monsoon was found around 1200 AD during a period of arid climate and Song-Yuan dynastic change. In the late 1920s, severe
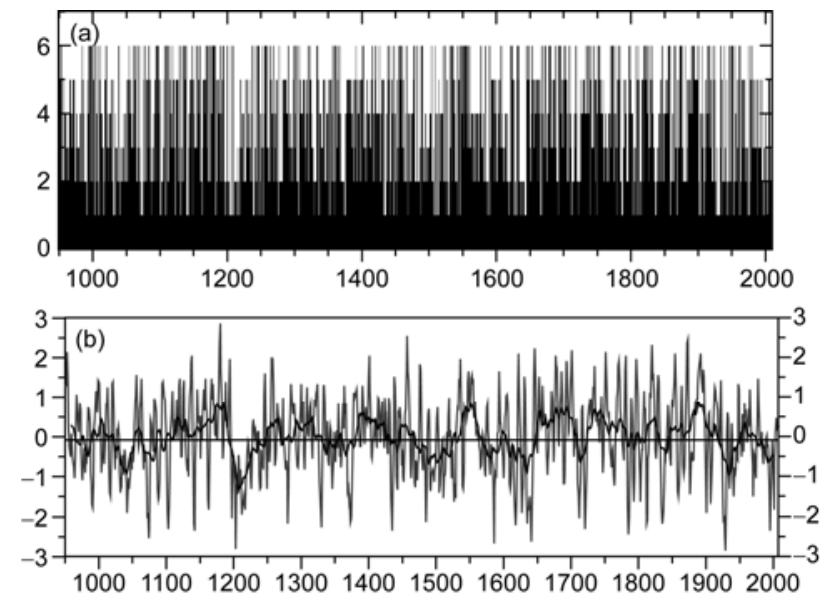

Figure 6 Millennial summer MDWI series in East Asia. (a) Original MDWI series from 950 to 2008; (b) 7-point and 21-point running mean MDWI series after standardized departure. dry climate event leading to locust swarms caused widespread crop failure and persistent famine in northern China [15]. In the last 500 years, summer monsoon flows that reached northwestern China had interannual and interdecadal variability, which resulted in drought and flood in the northwest region over the upper Yellow River valley [21]. In the 1990s, the strength of the East Asian summer monsoon decreased and the dry climate resulted in long-term low runoff in the Yellow River [15]. During the last 200 years, the East Asian summer monsoon had been the strongest and could arrive at the northern location in the later period of the 19th century. Wavelet transform analysis showed that there were several periodic oscillations with time scales of about 23.3 and 67 years as well as on a century time scale (data not shown). An oscillation with a time scale of around 10.1 years reached the 0.05 significance level. The last weak summer monsoon was mainly influenced by the interdecadal (67 years) oscillation caused by the large scale sea-land thermal contract change. In the summer monsoon area of eastern China, regional dry-wet variation has a quasi-70-year oscillation $[14,20]$. These results are similar to those of studies using reconstructed summer Asian-Pacific Oscillation (APO) long-term series and studying interdecadal precipitation oscillation over eastern China [22,23].

Regional and persistent (over many years) droughts or floods are severe climate disaster events for ecosystems. The numbers of regional annual drought (grades 4 and 5) or flood (grades 1 and 2) events in each decade for 950-2008 are shown in Figure 7. Five curves show the numbers of each decadal event from 0-10, including the regions and dry/wet events: (a) wet summer in North China, (b) dry summer in North China, (c) wet summer along the Yangtze River, (d) wet summer in South China, and (e) dry summer in South China. In North China, 9 years of wet summers occurred in the 1730 s and the 1890 s, respectively. During 1724-1737 and 1883-1898, two persistent wet processes appeared in North China. Along the Yangtze River, 8 and 7 years of wet summer climates were found in the 1560s and 1570 s, and the 1760 s, respectively. In South China, 8 years of summer wet climates were found in the 1170s, 1480s, 1630 s and 1870s. The most prominent decadal drought event occurred in the 1210 s and 9 years of dry summer climate appeared in the 1040s and the 1490s in North China. In South China, 8 years of dry summer climates occurred in the 1120s and the 1980s. A dry climate was more frequent in North China than in South China. During the last millennium, decadal dry or decadal wet persistent events occurred in North China.

\section{Conclusions}

Changes in the summer monsoon airflow and the subtropical monsoon rainy belt in eastern Asia on interannual and 

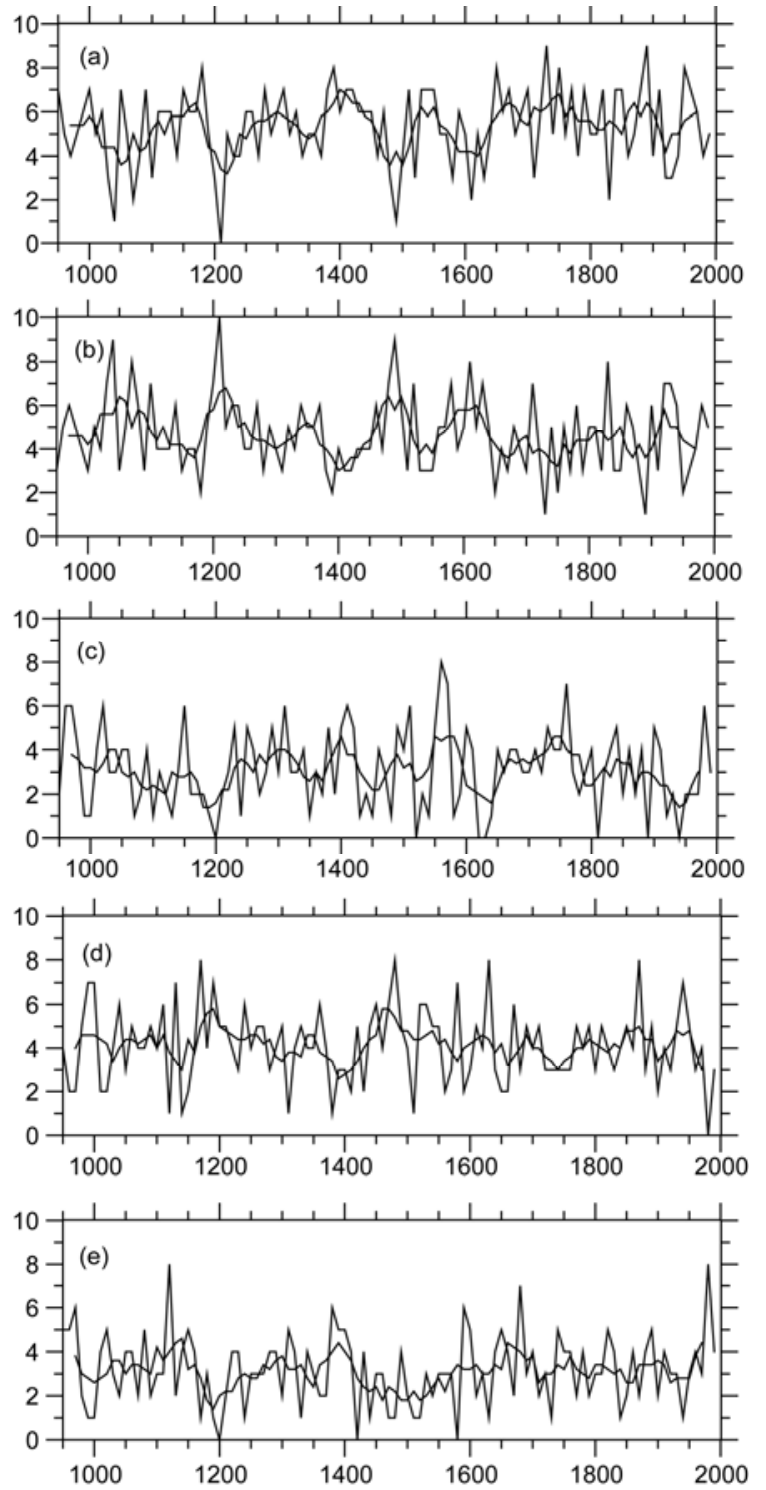

Figure 7 Numbers of regional summer drought (Grades 4 and 5) or flood (Grades 1 and 2) events in each decade during 950-2008. (a) Modes 4 to 6 (wet summer in North China); (b) Modes 1 to 3 (dry summer in North China); (c) Modes 3 to 4 (wet summer along the Yangtze River); (d) Modes 2 and 6 (wet summer in South China); (e) Modes 3 and 5 (dry summer in South China).

interdecadal time scales are widely paid attention to by government and the public. In this study, a millennial series of a monsoon dry-wet index (MDWI) was reconstructed based on in situ precipitation observational data collected since 1951 and historical dry-wet modes since 950 AD in eastern China. This index has the following basic features.

(1) In East Asia, the annual MDWI index describes the regional dry or wet (below or above normal precipitation) geographic distribution, the summer monsoon airflow advance northward and regional monsoon intensity. A high value of the MDWI indicates that the monsoon airflow transports more moisture to northern China, leading to a greater amount of precipitation. By contrast, a low value of the MDWI indicates that the monsoon airflow transports more moisture to southern China, leading to a greater amount of precipitation in southern China than in northern China.

(2) The MDWI index indicates the climate variations of the East Asian summer monsoon and is related to many other monsoon indexes, which are good indicators of the Meiyu intensity along the Yangtze River. The MDWI index represents both the atmospheric circulation anomaly and the dry-wet mode in the East Asian region. The circulation anomaly in East Asia is driven by the thermal contrasts between the Indian and Pacific Ocean and the Asian continent.

(3) There was interannual, interdecadal and centurialscale variability in the last millennial MDWI series. Interdecadal periodic variations, such as quasi-10-year, quasi-23-year and 60-70-year oscillations were found over several centuries. On the centurial scale, a long-term decrease of the MDWI was noted in the 20th century. On the interdecadal scale, the longest dry climate was observed in the 1200s. A severe decadal dry event in the late 1920s had disastrous consequences for human life and the ecosystem in northwest China.

(4) In northern China, persistent decadal wet or dry events appeared during the last millennium. At present, the MDWI is in a low period on the interdecadal time scale; there is below normal and above normal precipitation in northern and southern China, respectively. In the near future, the value of the MDWI is predicted to increase.

The authors would like to thank the anonymous reviewers for their helpful suggestions. This work was supported by the National Natural Science Foundation of China (40890053 and 90711003) and the Strategic Priority Research Program of the Chinese Academy of Sciences (XDA0509400).

1 Ding Y H, Wang Z Y, Sun Y. Inter-decadal variation of the summer precipitation in East China and its association with decreasing Asian summer monsoon. Part I: Observed evidences. Int J Climatol, 2008, 28: 1139-1161

2 Wang S W, Gong D Y, Ye J L, et al. Seasonal precipitation series of eastern China since 1880 and the variability (in Chinese). Acta Geogr Sin, 2000, 55: 281-293

3 Yang F L, Lau K M. Trend and variability of China precipitation in spring and summer linkage to sea-surface temperatures. Int J Climatol, 2004, 24: 1625-1644

4 Chang C P, Zhang Y S, Li T. Interannual and interdecadal variations of the East Asian summer monsoon and tropical Pacific SSTs. Part I: Roles of the subtropical ridge. J Clim, 2000, 13: 4310-4325

5 Gong D Y, Ho C H. Shift in the summer rainfall over Yangtze River valley in the late 1970s. Geophys Res Lett, 2002, 29: doi: 10.1029/ 2001GL014523

6 Guo Q Y. The summer monsoon intensity index in East Asia and its variation. Acta Geogr Sin, 1983, 38: 207-216

7 Shi N, Zhu Q G. East Asia winter and summer monsoon intensity index in 1873-1995 (in Chinese). Meteorol Sci Tech, 2000, 28: 14-18

8 Zhao P, Zhu Y N, Zhang R H. An Asian-Pacific teleconnection in summer tropospheric temperature and associated Asian climate variability. Clim Dyn, 2007, 29: 293-303

9 Zhu C W, He J H, Wu G X. East Asian monsoon index and its interannual relationship with largescale thermal dynamic circulation (in Chinese). Acta Meteorol Sin, 2000, 58: 391-401 
10 Zhang Q Y, Tao S Y, Chen L T. The inter-annual variability of East Asian summer monsoon indices and its association with the pattern of general circulation over East Asia (in Chinese). Acta Meteorol Sin, 2003, 61: 559-568

11 He M, Xu L, Song W L. Short range climate prediction of the onset and intensity of South China Sea summer monsoon (in Chinese). Meteorol Monthly, 2002, 28: 9-13

12 Hu H R, Qian W H. Identification of the northernmost boundary of East Asia summer monsoon. Prog Nat Sci, 2007, 17: 812-820

13 Yao C, Qian W H, Lin Z M. A circulation index reflecting the monsoon precipitation of South China (in Chinese). J Appl Meteorol Sci, 2011, 22: 302-311

14 Qian W H, Chen D, Zhu Y F, et al. Temporal and spatial variability of dryness/wetness in China during the last 530 years. Theor Appl Climatol, 2003, 76: 13-29

15 Qian W H, Lin X, Zhu Y F, et al. Climatic regime shift and decadal anomalous events in China. Clim Change, 2007, doi: 10.1007/s10584006-9234-z

16 Qian W H, Tang S Q. Identifying global monsoon troughs and global atmospheric centers of action on a pentad scale. Atmos Oceanic Sci Lett, 2010, 3: 1-6
17 Webster P J, Yang S. Monsoon and ENSO: Selectively interactive systems. Quart J Roy Meteorol Soc, 1992, 118: 877-926

18 Wang S W. Wetness variation in China over the last 500 years. In: Zhang J, ed. The Reconstruction of Climate in China for Historical Times. Beijing: Science Press, 1988. 66-78

19 Wang S W, Zhao Z C, Chen Z H, et al. Drought/flood variations for the last two thousand years in China and comparison with global climatic change. In: Ye D Z, Fu C B, Chao J P, et al., eds. The Climate of China and Global Climate. Springer Berlin Heidelberg New York: China Ocean Press, 1987. 20-29

20 Qian W H, Hu Q, Zhu Y F, et al. Centennial-scale dry-wet variations in East Asia. Clim Dyn, 2003, 21: 77-89

21 Qian W H, Shan X L, Chen D, et al. Droughts near the northern fringe of the East Asian summer monsoon in China during 14702003. Clim Change, 2011, doi: 10.1007/s10584-011-0096-7

22 Liu G, Zhao P, Chen J M. A 150-year reconstructed summer AsianPacific Oscillation index and its association with precipitation over eastern China. Theor Appl Climatol, 2010, doi: 10.1007/s00704-010- 0294-7

23 Zhou X J, Zhao P, Liu G. Asian-Pacific Oscillation index and variation of East Asian summer monsoon over the past millennium. Chinese Sci Bull, 2009, 54: 3768-3771

Open Access This article is distributed under the terms of the Creative Commons Attribution License which permits any use, distribution, and reproduction in any medium, provided the original author(s) and source are credited. 